\title{
PKC-Mediated ZYG1 Phosphorylation Induces Fusion of Myoblasts as well as of Dictyostelium Cells
}

\author{
Aiko Amagai, ${ }^{1}$ Harry MacWilliams, ${ }^{2}$ Takahiro Isono, ${ }^{3}$ Mariko Omatsu-Kanbe, ${ }^{4}$ \\ Shinya Urano, ${ }^{1}$ Kazuo Yamamoto, ${ }^{1}$ and Yasuo Maeda ${ }^{1}$ \\ ${ }^{1}$ Graduate School of Life Sciences, Tohoku University, Sendai 980-8577, Japan \\ ${ }^{2}$ Zoologisch Institute, Ludwig-Maximilians Universitat, 80333 München, Germany \\ ${ }^{3}$ Central Research Laboratory, Shiga University of Medical Science, Otsu, Shiga 520-2192, Japan \\ ${ }^{4}$ Department of Physiology, Shiga University of Medical Science, Otsu, Shiga 520-2192, Japan \\ Correspondence should be addressed to Aiko Amagai, aiamagai@mail.tains.tohoku.ac.jp \\ Received 12 June 2011; Revised 1 October 2011; Accepted 1 October 2011 \\ Academic Editor: Andre Van Wijnen \\ Copyright ( 2012 Aiko Amagai et al. This is an open access article distributed under the Creative Commons Attribution License, \\ which permits unrestricted use, distribution, and reproduction in any medium, provided the original work is properly cited.
}

We have previously demonstrated that a novel protein ZYG1 induces sexual cell fusion (zygote formation) of Dictyostelium cells. In the process of cell fusion, involvements of signal transduction pathways via $\mathrm{Ca}^{2+}$ and $\mathrm{PKC}$ (protein kinase $\mathrm{C}$ ) have been suggested because zygote formation is greatly enhanced by PKC activators. In fact, there are several deduced sites phosphorylated by PKC in ZYG1 protein. Thereupon, we designed the present work to examine whether or not ZYG1 is actually phosphorylated by PKC and localized at the regions of cell-cell contacts where cell fusion occurs. These were ascertained, suggesting that ZYG1 might be the target protein for PKC. A humanized version of zyg1 cDNA (mzyg1) was introduced into myoblasts to know if ZYG1 is also effective in cell fusion of myoblasts. Quite interestingly, enforced expression of ZYG1 in myoblasts was found to induce markedly their cell fusion, thus strongly suggesting the existence of a common signaling pathway for cell fusion beyond the difference of species.

\section{Introduction}

Some species of Dictyostelium exhibit dimorphism in development: sorocarp formation as an asexual development and macrocyst formation as a sexual development. In the asexual development, amoeboid cells grow and multiply feeding on bacteria during the vegetative growth phase. Upon exhaustion of external nutrients, starving cells stop growing and enter the differentiation phase. They gather together to form cell aggregates. A tip is formed on the top of each cell aggregate, which then migrates as a slug-shaped mass. After migration, the slug changes its shape dramatically to form a sorocarp consisting of a stalk with an apical mass of spores.

In the sexual development, Dictyostelium mucoroides 7 (Dm7), one species of cellular slime molds, forms macrocysts homothallically without its opposite mating type. Macrocyst formation in $\mathrm{Dm} 7$ is characterized by the formation of large aggregates after starvation, which are then subdivided into smaller masses (precysts), each of which is surrounded by a fibrillar sheath. At the center of each precyst, there arises a cytophagic cell (a giant cell), which in turn engulfs all the other cells in the precyst. The engulfed cells (endocytes) are eventually broken down into granular remnants. The enlarged cytophagic cell finally becomes surrounded by a thick wall to form a mature macrocyst [1]. After a resting period, the macrocyst germinates to release several amoeboid cells and initiates a new life cycle [2]. Other species of cellular slime molds, such as Dictyostelium discoideum (D. discoideum), form macrocysts heterothallically with their opposite mating types $[3,4]$.

The giant cell which appears during macrocyst formation is clarified as a zygote which is formed by cell fusion and subsequent nuclear fusion [5]. Several molecules have been identified as regulators of zygote formation. Ethylene has been known as a potent inducer, while cAMP as an inhibitor $[5,6] . \mathrm{Ca}^{2+}$ is also able to induce zygote formation because the efficiency of zygote formation is significantly elevated by the presence of extracellular $\mathrm{Ca}^{2+}[6-8] . \mathrm{Ca}^{2+}$ is supposed to activate $\mathrm{PKC}$ (protein kinase $\mathrm{C}$ ) in the signal transduction pathways involved in zygote formation. In this connection, 
phorbol esters such as TPA (12-O-tetradecanoyl phorbol-13acetate), potent activators of PKC, have been shown to enhance zygote formation [9, 10]. In contrast, staurosporine, an inhibitor of kinases including PKC, inhibits zygote formation markedly $[9,10]$ and therefore macrocyst formation [11]. It is quite possible that zygotes in heterothallic strains may be formed by essentially the same mechanism as that in homothallic strains $[10,12]$.

In the process of myoblast fusion, cells cease dividing and change their morphology from fibroblast-like to spindle (bipolar) shape. End-to-end alignment of cells is formed along with lateral-to-lateral alignment in a process termed recognition-alignment. Alignment is followed by adhesion, defined as the stage immediately prior to membrane union. The highly elongated cells of typical myoblast fusion, in which nuclei were arranged in a single file, were finally formed. Many molecules which regulate myoblast fusion have been reported $[13,14]$. Among them, it has been well documented that the signaling pathway mediated by $\mathrm{Ca}^{2+}$ and PKC is closely involved in cell fusion of myoblasts during myogenesis [15-19]. Since the signaling pathway via $\mathrm{Ca}^{2+}$ and PKC is involved in myoblast fusion as well as in Dictyostelium cell fusion, we have interested to know if there is a functionally ZYG1-like protein capable of inducing cell fusion in myoblasts.

As a gene involved in sexual fusion (zygote formation) during Dictyostelium development, zyg1 cDNA was isolated from $D m 7$ by differential screening [20]. The zyg1 gene encodes a novel protein (ZYG1; deduced Mr $29.4 \times 10^{3}$ ) consisting of 268 amino acids. It was predicted that it has neither transmembrane domains nor specified signal sequences although ZYG1 protein has predicted PKC-mediated phosphorylation sites. The expression of $z y g 1$ begins after $2 \mathrm{~h}$ of starvation and reaches its maximum level at $8 \mathrm{~h}$ under submerged culture conditions. The zyg1 expression pattern is quite similar to the temporal change of zygote formation during sexual development (marcocyst formation) [11]. In the transformants overexpressing zyg1, the formation of zygotic giant cells is greatly enhanced, and macrocysts are formed even under unfavorable conditions for macrocyst formation in wild type Dm7 cells [20]. Interestingly, the zyg1 expression is induced by ethylene, a potent plant hormone [21].

In general, the activated PKC is known to translocate to the cell membrane in oocytes [22]. Thus, it is possible that ZYG1 may translocate to the cell membrane where cell fusion occurs and is phosphorylated by PKC because ZYG1 is a likely substrate for PKC.

The present work was undertaken to answer the following questions. (1) Where is ZYG1 protein localized in Dictyostelium cells? (2) Is ZYG1 protein actually phosphorylated by PKC? (3) Can ZYG1 protein induce cell fusion in myoblasts as well as in Dictyostelium cells? The results obtained have showed that ZYG1 protein phosphorylated by $\mathrm{PKC}$ is localized at the region where cell fusion occurs and that ZYG1 protein also induces cell fusion in myoblasts.

\section{Materials and Methods}

2.1. Cell Culture and Developmental Conditions. Dictyostelium discoideum $\mathrm{Ax}-2$, its transformants (GFPCONT and
$\mathrm{GFP} / \mathrm{ZGG} 1^{\mathrm{OE}}$ ), and mouse myoblasts $(\mathrm{C} 2 \mathrm{C} 12)$ were used in this work. Vegetative cells of Ax-2 were grown axenically in PS-medium (1\% Special Peptone (Oxoid: Lot no. 333 56412), 0.7\% Yeast extract (Oxoid), 1.5\% D-glucose, $0.11 \%$ $\mathrm{KH}_{2} \mathrm{PO}_{4}, 0.05 \% \mathrm{Na}_{2} \mathrm{HPO}_{4} \cdot 12 \mathrm{H}_{2} \mathrm{O}, 40 \mathrm{ng} / \mathrm{mL}$ vitamin $\mathrm{B}_{12}$, and $80 \mathrm{ng} / \mathrm{mL}$ folic acid) containing $200 \mu \mathrm{g} / \mathrm{mL}$ of streptomycin and $10 \mu \mathrm{g} / \mathrm{mL}$ tetracycline. Transformants derived from $\mathrm{Ax}-2$ cells were grown axenically by the shaking culture in PS-medium containing $200 \mu \mathrm{g} / \mathrm{mL}$ of streptomycin, $10 \mu \mathrm{g} /$ $\mathrm{mL}$ of tetracycline, and $50 \mu \mathrm{g} / \mathrm{mL}$ of G418. To allow cells to differentiate, cells were harvested during the exponential growth phase, washed once in BSS (Bonner's salt solution; $10 \mathrm{mM} \mathrm{NaCl}, 10 \mathrm{mM} \mathrm{KCl}$, and $2.7 \mathrm{mM} \mathrm{CaCl}_{2}$ ) [23] as starvation medium, and developed under the submerged conditions in BSS at $5 \times 10^{5}$ cells $/ \mathrm{cm}^{2}$. For the immunocytochemical observations, starved cells were settled on coverslips which were placed in glass dishes $(3.6 \mathrm{~cm}$ diameter $)$. This was followed by incubation at $22^{\circ} \mathrm{C}$ with or without $5 \mathrm{nM}$ of TPA (Sigma).

Mouse C2C12 cells (myoblasts) were cultured at $37^{\circ} \mathrm{C}$ in $5 \% \mathrm{CO}_{2}$ at $95 \%$ humidity in McCoy's $5 \mathrm{~A}$ (GIBCO) supplemented with $10 \%$ of FBS (fetal bovine serum; Invitrogen, CA), $0.03 \%$ of L-glutamine, and $80 \mu \mathrm{g} / \mathrm{mL}$ of kanamycin.

\subsection{Vector Constructs}

2.2.1. The Vector Construct for Expression of gfp/zyg1 Fusion Gene. The v18-l-s65tgfp (8181 bps) vector containing v18 promotor and s65tgfp (green fluorescent protein with fast oxidizing mutation S65T) gene was used as the starting material. Ubi and lacl genes inserted between $v 18$ promotor and s65tgfp gene (984 bps) were deleted from this vector. To produce the $g f p / z y g 1$ fusion gene, the vector was treated by XhoI. zyg1 cDNA without initiation codon (ATG) was also treated by XhoI. A XhoI-treated zyg1 (-ATG) gene was inserted into a $X$ hoI-treated $v 18$-l-s65tgfp vector. Vectors in which $z y g 1$ gene was inserted in the downstream of s65tgfp gene at the sense direction were clonally selected ( $g f p / z y g 1$ fusion gene).

2.2.2. The Vector Construct for Expression of ha/mzyg1 Fusion Gene. A humanized version (mzygl) of zyglcDNA (AB006956) was synthesized so that each amino acid codon was replaced by that most commonly found in mammalian cells (DNA 2.0 Inc). mzyg1 treated by BamHI and EcoRI was inserted into pUCD2 SR $\alpha$ [24] treated by BamHI and EcoRI to create the ha/mzyg1 fusion gene, in which the mzyg1 gene was inserted in the downstream of a $h a(3 \times$ haemagglutinin $)$ at the sense direction ( $h a / m z y g 1$ fusion gene). The pUCD2 $\mathrm{SR} \alpha$ vector was kindly gifted from Dr. K. Ohashi (Tohoku University).

2.2.3. The Vector Construct for Expression of gfp and mzyg1 Genes. For statistical analyses, a pIRES2-AcGFP vector (Clontech) was used. mzyg1 treated by XbaI and EcoRI was inserted into the pIRES2-AcGFP vector treated by NheI and $E c o$ RI to create a vector-expressing $g f p$ and $m z y g 1$ genes ( $g f p$ and $m z y g 1$ ). 
2.3. Transformation of Ax-2 Cells. Ax-2 cells were grown by shake culture, harvested, and washed once with BSS. Starved cells were then washed twice with EB (electroporation buffer; $10 \mathrm{mM}$ phosphate buffer ( $\mathrm{pH} 6.2$ ) containing $50 \mathrm{mM}$ sucrose) and suspended in $\mathrm{EB}$ at $3 \times 10^{7}$ cells $/ \mathrm{mL}$. Introduction of the vector constructs into Ax-2 cells was performed by electroporation, as described by Howard et al. [25], using $10 \mu \mathrm{g}$ of the vector containing $g f p$ insert and $18 \mu \mathrm{g}$ of the vector containing $g f p / z y g 1$ insert, to gain the transformants $\mathrm{GFP}^{\mathrm{CONT}}$ and GFP/ZYG1 ${ }^{\mathrm{OE}}$, respectively. The original transformant pool was first selected by incubation in PS medium containing $10 \mu \mathrm{g} / \mathrm{mL}$ of G418 and finally cloned by selection in $50 \mu \mathrm{g} / \mathrm{mL}$ of G418.

2.4. Western Blot Analysis. GFPCONT and GFP/ZYG1 ${ }^{\mathrm{OE}}$ cells $\left(1 \times 10^{7}\right)$ were boiled for $5 \mathrm{~min}$ in SDS-sample buffer $(90 \mu \mathrm{L})$ (2\% SDS, $62.5 \mathrm{mM}$ Tris- $\mathrm{HCl}$, pH 6.8, 10\% glycerol, $42 \mathrm{mM}$ dithiothreitol, and $0.005 \%$ bromophenol blue) and then cooled on ice. The samples $(3 \mu \mathrm{L})$ were separated by $10 \%$ SDS-PAGE and transferred on Immunoblot PVDF membranes (Bio-Rad). The membranes were blocked overnight with TBS-T (20 mM Tris- $\mathrm{HCl}$ (pH 8.0), $150 \mathrm{mM} \mathrm{NaCl}$, and $0.05 \%$ Tween 20 ) containing $0.5 \%$ BSA (bovine serum albumin, Sigma) at RT (room temperature). Subsequently, the membranes were probed by rabbit Phospho-(Ser) PKC Substrate antibody (Cell Signaling) diluted 1,000 times with enhancer A solution (Wako) for $1 \mathrm{~h}$ at RT. After two washings in TBS-T (10 min for each), the membranes were stained with goat HRP- (horseradish-peroxidase-) conjugated anti-rabbit secondary antibody (Amersham Biosciences) diluted 5,000 times with enhancer B solution (Wako) for $1 \mathrm{~h}$. ImmunoStar (Long Detection, Wako) was used for the detection of HRP. After this detection, the membranes were washed in stripping solution (2-mercaptoethanol; $347 \mathrm{~mL}, 10 \%$ SDS; $10 \mathrm{~mL}$, $0.5 \mathrm{M}$ Tris- $\mathrm{HCl}$ (pH 6.7); $6.25 \mathrm{~mL}$, DW; $33.4 \mathrm{~mL}$ ) for $30 \mathrm{~min}$ at $50^{\circ} \mathrm{C}$, blocked $1 \mathrm{~h}$ with TBS-T containing $5 \%$ skim milk, and then probed by the rabbit anti-GFP antibody (Invitrogen) diluted 500 times with TBS-T containing 5\% skim milk for $1 \mathrm{~h}$ at RT. After two washings in TBS-T (10 min for each), the membranes were stained for $1 \mathrm{~h}$ with the goat HRP-conjugated anti-rabbit secondary antibody (Amersham Biosciences) diluted 5,000 times with TBS-T. ImmunoStar (Long Detection, Wako) was used for the detection of HRP.

\subsection{Immunocytochemical Staining of GFP ${ }^{C O N T}$ and} GFP/ZYG1 ${ }^{O E}$ Cells. Growing GFPCONT and GFP/ZYG1 ${ }^{\mathrm{OE}}$ cells were harvested, washed once with BSS, and resuspended in BSS at $2.5 \times 10^{6}$ cells $/ \mathrm{mL}$. Two $\mathrm{mL}$ of the cell suspension was dropped on coverslips placed in glass dishes (diameter; $3.6 \mathrm{~cm}$ ) and incubated for $2 \mathrm{~h}$. The cells adhering to the coverslips were fixed with $4 \%$ paraformaldehyde for $20 \mathrm{~min}$ or ice-cold methanol for $10 \mathrm{~min}$. In the case of fixation by paraformaldehyde, it was followed by treatment with $0.2 \%$ Triton X-100 in PBS containing 2\% FBS for $30 \mathrm{~min}$ at RT to obtain permeability. Then, the samples were soaked in PBS ( $10 \mathrm{mM}$ phosphate $\mathrm{Na}_{2} / \mathrm{K}$ buffer, $\mathrm{pH} 7.0,0.9 \% \mathrm{NaCl}$ ), blocked with PBS containing 2\% FBS (fetal bovine serum) for $30 \mathrm{~min}$ at RT, and probed with the rabbit Phospho-(Ser)
PKC Substrate antibody (Cell Signaling) diluted 300 times with PBS containing $2 \% \mathrm{FBS}$, for $1 \mathrm{~h}$ at RT. The samples were washed by three changes of PBS and then stained with the goat rhodamine-conjugated secondary anti-rabbit IgG $(\mathrm{H}+$ L) (Thermo) for $1 \mathrm{~h}$ at RT. After washing in PBS, samples were mounted in PBS containing 20\% glycerol.

\subsection{Introduction of Vectors into C2C12 Cells (Myoblasts).} $\mathrm{C} 2 \mathrm{C} 12$ cells (myoblasts) were placed on coverslips and transfected with the vector containing a ha gene, a ha/mzygl fusion gene, a $g f p$ gene, or $g f p$ and $m z y g 1$ genes using Lipofectamine 2000 (Invitrogen) according to the manufacturer's instruction. After $6 \mathrm{~h}$ of transfection in Opti-MEM (Invitrogen) without FBS, samples were washed twice with PBS and incubated with DMEM (Dulbecco's Modified Eagle Medium, Invitrogen) containing $10 \% \mathrm{FBS}$ and $80 \mu \mathrm{g} / \mathrm{mL}$ of kanamycin for $24 \mathrm{~h}$ at $37^{\circ} \mathrm{C}$ in $5 \% \mathrm{CO}_{2}$ at $95 \%$ humidity.

\subsection{Immunocytochemical Staining of C2C12 Cells Expressing} HA or HA/ZYG1 Protein. After transfection, the samples were fixed with PBS containing 4\% paraformaldehyde for 20 min and permeabilized with $0.2 \%$ Triton X-100 in PBS containing $2 \%$ FBS for $30 \mathrm{~min}$ at RT, followed by blocking with PBS containing 2\% FBS for 30 min at RT. After three washings in PBS, the samples were stained with the mouse anti-HA antibody (Roche Applied Science) diluted 400 times with PBS containing $2 \%$ FBS, for $1 \mathrm{~h}$ at RT. Then they were washed with three changes of PBS and stained with the goat FITC-conjugated secondary anti-mouse IgG $(\mathrm{H}+\mathrm{L})$ (Alexa Fluor 488, Invitrogen) in PBS containing 2\% FBS for $1 \mathrm{~h}$ at RT. After washings in PBS, the samples were mounted in PBS containing 20\% glycerol and DAPI (4'-6-diamidino-2-phenylindole) (final concentration: $2.5 \mu \mathrm{g} / \mathrm{mL}$ ) (Wako, Japan).

2.8. Photographs. Photographs were taken under fluorescence microscope (Axioskop, Zeiss) or confocal microscope (Fluoview FV 1000, Olympus).

\section{Results}

3.1. Localization of GFP/ZYG1 Fusion Protein. From our previous studies [10,20], ZYG1 was expected to translocate to the cell membrane where cell fusion occurs and probably coupled with its phosphorylation by PKC. To examine this possibility, the $g f p / z y g 1$ fusion gene was introduced into $D$. discoideum Ax-2 cells. In the present work, we used Ax-2 cells, instead of D. mucoroides 7 (Dm7) that had been used in our previous works, because Ax-2 cells with 10-11 $\mu$ m of diameter are bigger than Dm7 cells with 6-7 $\mu \mathrm{m}$ of diameter and more convenient for cytological studies. In addition, it is suggested that the mechanism of zygote formation might be fundamentally common $[10,12]$. The vector containing only a $g f p$ gene was also introduced into Ax-2 cells as a control. Cells overexpressing GFP/ZYG1 (GFP/ZYG1 ${ }^{\mathrm{OE}}$ ) and overexpressing GFP (GFPCONT) were selected by $50 \mu \mathrm{g} / \mathrm{mL}$ of G418, and the localization of GFP/ZYG1 fusion protein or GFP protein was monitored under fluorescence and confocal microscopes. 


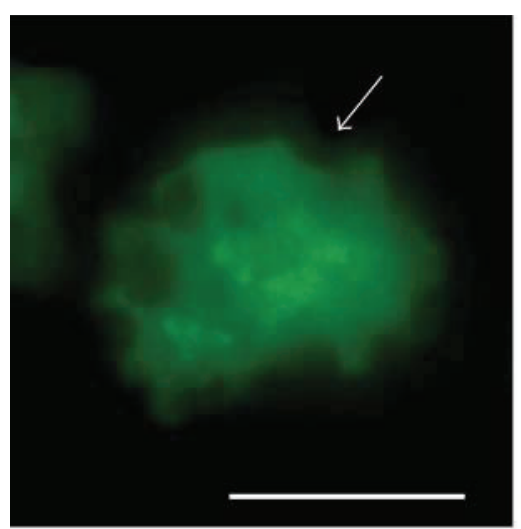

(a)

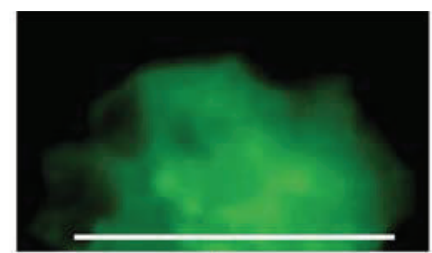

(b)

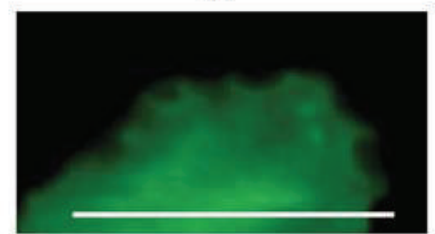

(c)

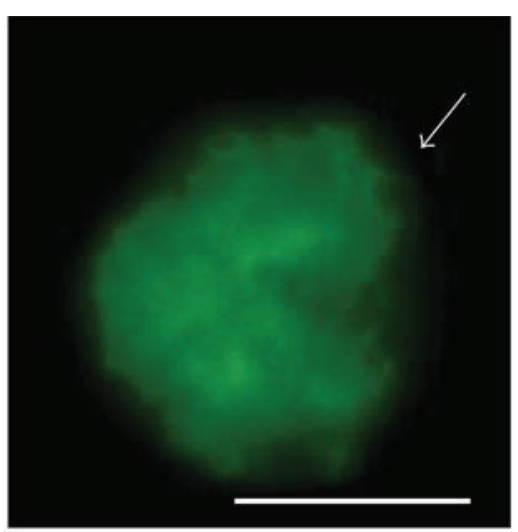

(d)

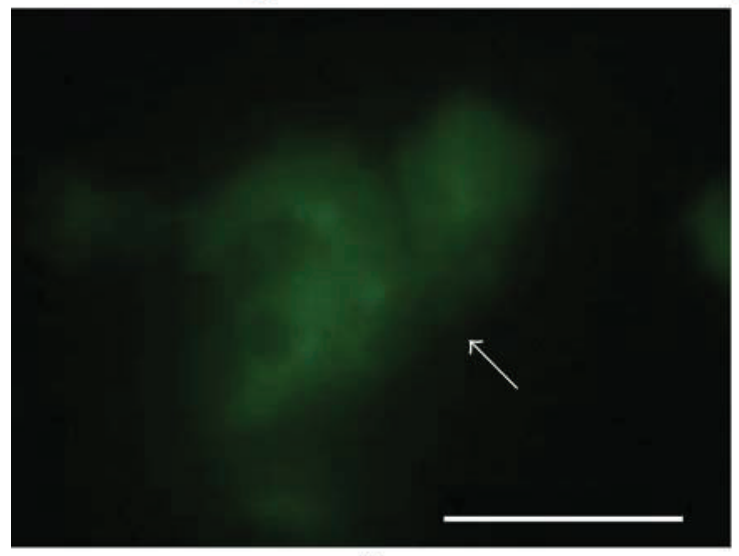

(e)

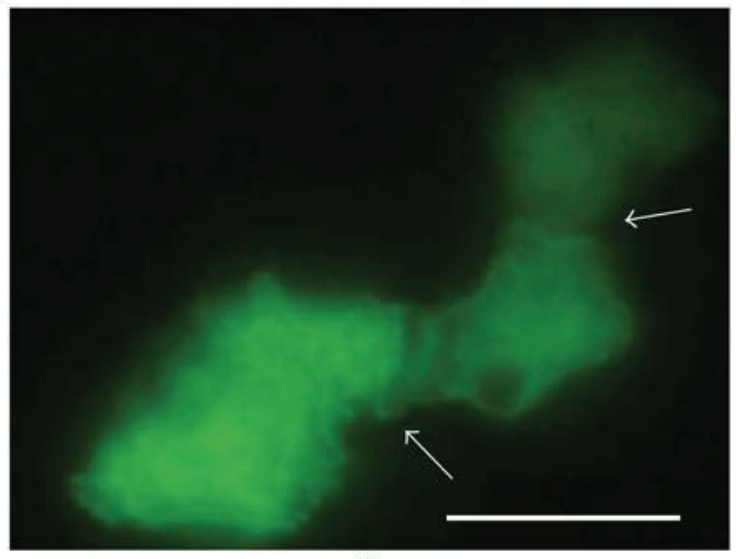

(f)

FIGURE 1: Localization of GFP and GFP/ZYG1 fusion protein. GFPCONT and GFP/ZYG1 ${ }^{\mathrm{OE}}$ cells are starved for $2 \mathrm{~h}$, fixed with $4 \%$ paraformaldehyde for $20 \mathrm{~min}$, and observed under a fluorescence microscope. GFP protein in GFPCONT cells and GFP/ZYG1 fusion protein in $\mathrm{GFP} / \mathrm{ZYG} 1^{\mathrm{OE}}$ cells are shown as the green color of GFP. GFP/ZYG1 fusion protein is preferentially localized at the periphery of vesicles (c, d; arrow) and at the phagocytic cups which are attached to form cell-cell contacts (f; arrows). On the other hand, in GFPCONT cells, GFP protein is uniformly distributed in the cytoplasm ( $\mathrm{a}, \mathrm{b}$; arrow), and its localization at the region of cell-cell contacts is not observed (e; arrow). This indicates that its localization is due to the presence of ZYG1, but not to GFP itself. Photographs of (b) and (c) are the magnified (a) and (d), respectively, and adjusted to get brighter images. Bars: $20 \mu \mathrm{m}$.

GFP protein in GFPCONT cells and GFP/ZYG1 fusion protein in GFP/ZYG1 ${ }^{\mathrm{OE}}$ cells were observed as the green color of GFP. When GFPCONT cells were developed for $2 \mathrm{~h}$ after starvation, GFP protein was uniformly distributed in the cytoplasm (Figures 1(a) and 1(b)). On the other hand, in GFP/ ZYG1 ${ }^{\mathrm{OE}}$ cells, most GFP/ZYG1 fusion protein was localized at the periphery of vesicles (Figures 1(c) and 1(d); arrow), particularly around the phagocytic cups. The phagocytic cups became larger and attached to each other when cell-cell contacts were formed (Figure 1(f); arrows). Since the localization of GFP at the periphery of vesicles and the region of cell-cell contacts was never observed in GFPCONT cells (Figures 1(a) and 1(e); arrows), it is most likely that its localization is due to the presence of ZYG1, but not to GFP itself. Successive observation of intact cells observed under a fluorescence microscope has showed that GFP/ZYG1 fusion protein translocates to the cell cortex and then detaches from the cell cortex within $10 \mathrm{sec}$ (Figure S1 see in supplementary material available online at doi:10.1155/2012/657423). Thus, the ZYG1 localization seemed to change temporarily.
When optical sections of GFP/ZYG1 ${ }^{\mathrm{OE}}$ cells under a confocal microscope were observed, a part of two contacted cells seemed to fuse to each other because demarcation was lost in sections 2 and 3 of Figure 2 (DIC; yellow arrows). Considering the merged images of DIC (Differential Interference Contrast) and green fluorescence emitted from GFP, it is quite possible that GFP/ZYG1 fusion protein is preferentially localized at the region of cell fusion (Figure 2). It was also observed that GFP protein was localized in nuclei (shown as red in Figure 2). These results showed that ZYG1 was predominantly localized at the regions of cell-cell contacts and cell fusion.

3.2. Phosphorylation of ZYG1 by PKC. To know if ZYG1 is phosphorylated by PKC (protein kinase C), ZYG1 phosphorylation in GFP/ZYG $1^{\mathrm{OE}}$ cells was examined by Western blotting using the antibody that specifically recognized the serine residues phosphorylated by PKC. Results showed that a small amount of GFP/ZYG1 fusion protein $(67.4 \mathrm{kDa})$ was 

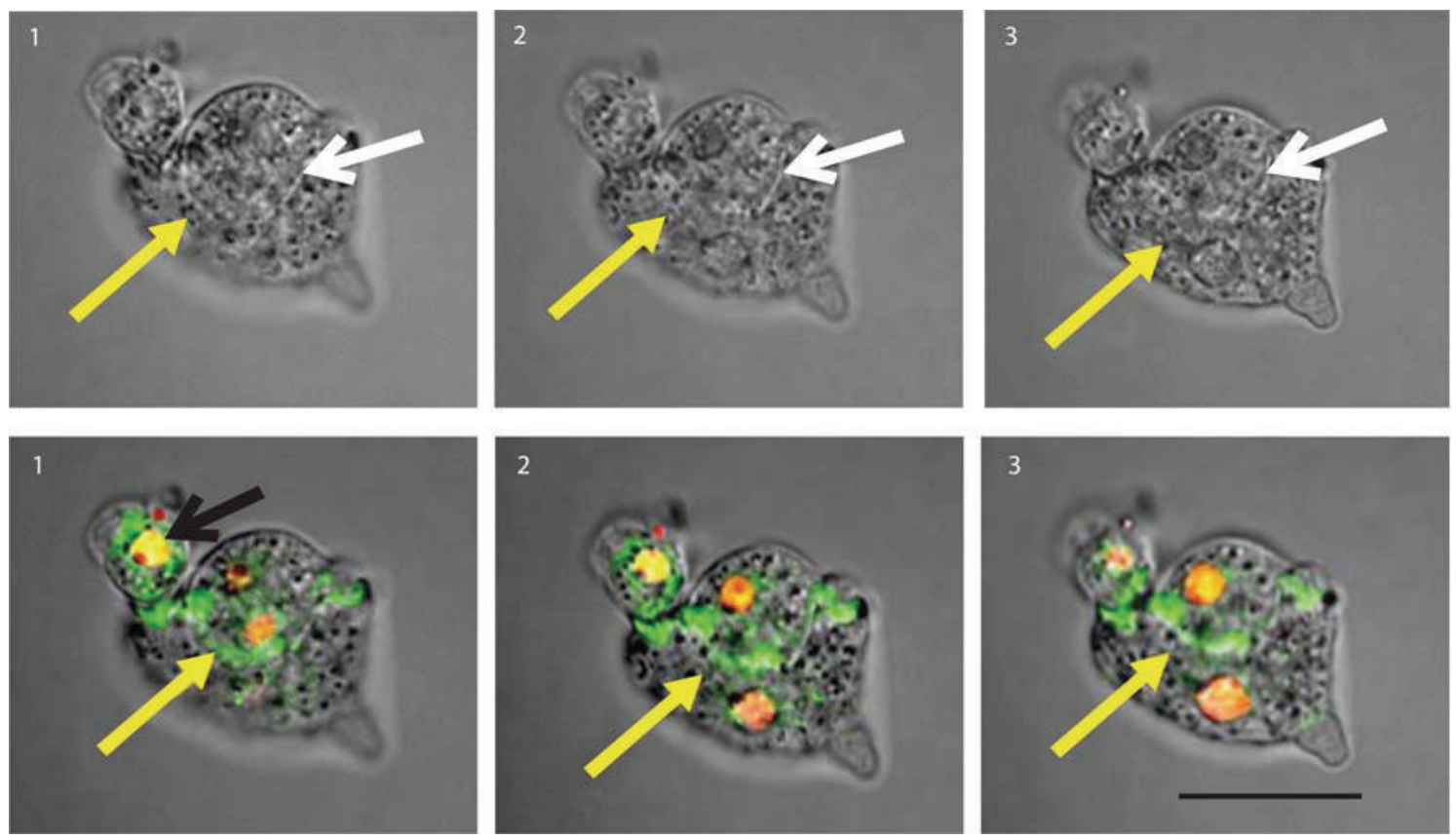

Figure 2: Behavior of ZYG1 during cell fusion. GFP/ZYG1 ${ }^{\mathrm{OE}}$ cells were starved for $2 \mathrm{~h}$ and fixed with methanol for $10 \mathrm{~min}$. Pictures of their serial sections $(1 \sim 3: 4 \mu \mathrm{m}$ thick) were taken under a confocal microscope. Pictures on the upper side show DIC images and those on the lower side the merged images of DIC, GFP, and DAPI staining. The color of DAPI staining is shown as red. In the DIC images (upper panels), the boundaries shown by white arrows are clear in all sections. On the other hand, the boundary shown by a yellow arrow is clearly observed in section 1, while the demarcation becomes unclear in sections 2 and 3 . This indicates that the two cells are fusing around here (2, 3). In merged images (lower panels), GFP/ZYG1 fusion protein is localized at the region of cell fusion (2, 3; yellow arrows). Nuclei become yellow by merging GFP with DAPI staining. Bar: $20 \mu \mathrm{m}$.

phosphorylated by PKC during development (Figure 3(a)). The same bands were also recognized by the detection of GFP using the anti-GFP antibody (Figure 3(b)). In GFPCONT cells, the band of GFP protein was detected at $38 \mathrm{kDa}$ (Figure S2 see in supplementary material available online at doi:10.1155/2012/657423). Since the antibody (Phospho(Ser) PKC Substrate antibody) used in this study reacts specifically to the phosphoserine substrate phosphorylated by cPKC (conventional PKC which requires $\mathrm{Ca}^{2+}$ and DAG (diacylglycerol) for maximal activity), it is clear that ZYG1 protein is actually phosphorylated by cPKC.

The phosphorylation of ZYG1 protein was examined also by immunocytochemical staining. As TPA, a potent activator of cPKC, is known to enhance the formation of zygotes [9], experiments were carried out with or without TPA $(5 \mathrm{nM})$. In $\mathrm{GFP} / \mathrm{ZYG1}{ }^{\mathrm{OE}}$ cells, GFP/ZYG1 fusion protein shown as the green color of GFP was localized at the region of cell-cell contacts (Figure 4(d); arrow). On the other hand, the localization of GFP protein at the region of cell-cell contacts was not observed in GFPCONT cells (Figure 4(c); arrow). This indicates that ZYG1 protein, but not GFP, localizes at the region of cell-cell contacts in GFP/ZYG1 ${ }^{\mathrm{OE}}$ cells, as shown already in Figure 1. The protein phosphorylated by PKC shown as the red color of Rhodamine was also localized at the region of cell-cell contacts in GFP/ZYG1 ${ }^{\mathrm{OE}}$ cells (Figure 4(f); arrow). This localization was not observed in GFPCONT cells (Figure 4(e); arrow). When GFP was merged with Rhodamine, the image exhibited yellow color in GFP/ZYG1 ${ }^{\mathrm{OE}}$ cells (Figure 4(h); arrow). This means that ZYG1 protein was colocalized
GFPCONT

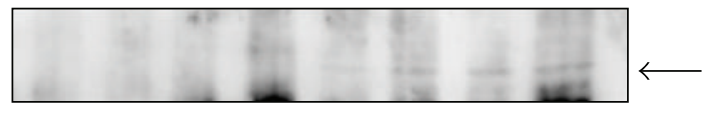

(a)

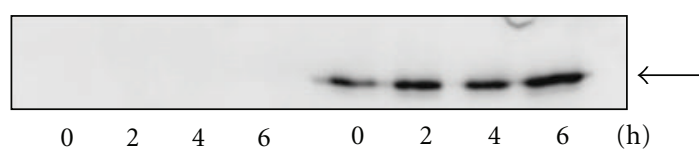

(b)

Figure 3: Phosphorylation of GFP/ZYG1 fusion protein by cPKC. $\mathrm{GFP}^{\mathrm{CONT}}$ and GFP/ZYG1 ${ }^{\mathrm{OE}}$ cells were collected at 2-hour intervals after starvation. Each sample was separated by $10 \%$ SDS-PAGE, followed by Western blottings using the rabbit Phospho-(Ser) PKC Substrate antibody and the rabbit anti-GFP antibody. Hours after starvation are designated at the bottom. The GFP/ZYG1 fusion protein $(67.4 \mathrm{kDa})$ is phosphorylated by cPKC (a; arrow), while no bands around $67.4 \mathrm{KD}$ are detected in the samples obtained from GFPCONT cells. GFP/ZYG1 ${ }^{\mathrm{OE}}$ cells also express GFP protein, as detected by the anti-GFP antibody (b; arrow).

with the proteins phosphorylated by $\mathrm{cPKC}$ at the regions of cell-cell contacts (Figure 4, arrows). Naturally enough, the colocalization of GFP and Rhodamine was not observed in GFP $^{\text {CONT }}$ cells (Figure 4(g); arrow).

Multinucleate cells were formed more frequently in GFP/ $\mathrm{ZYG1}^{\mathrm{OE}}$ cells that had been incubated with TPA, as compared 


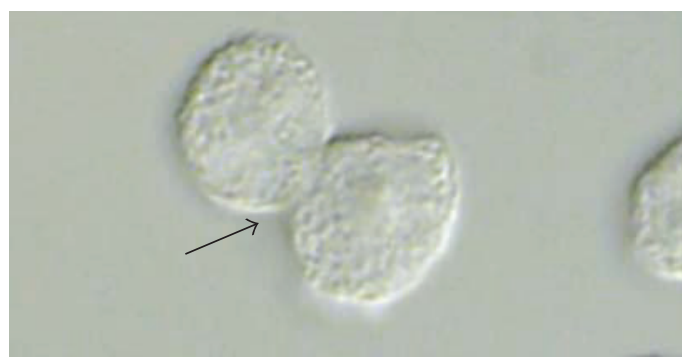

(a)

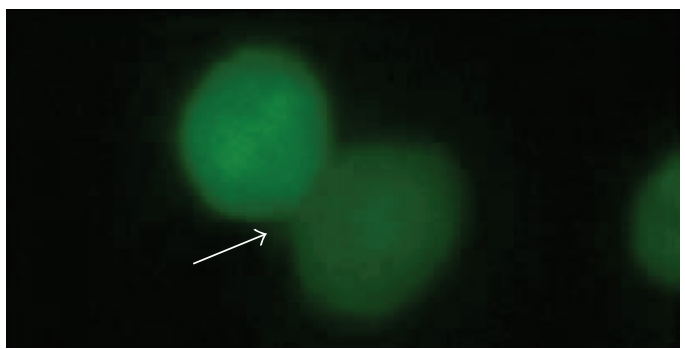

(c)

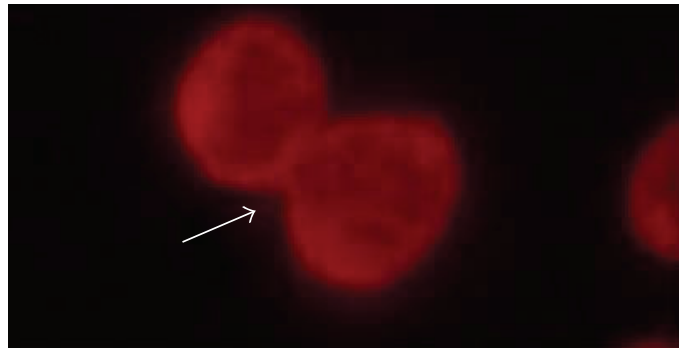

(e)

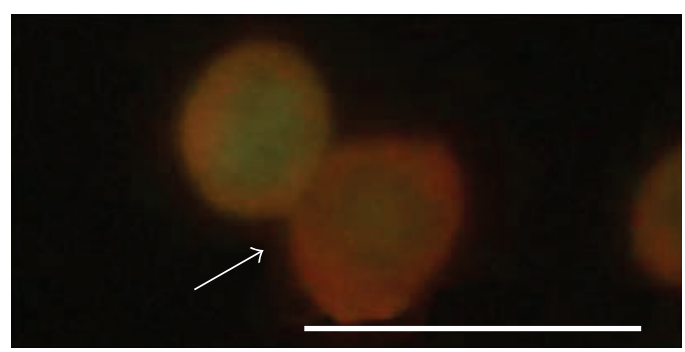

(g)

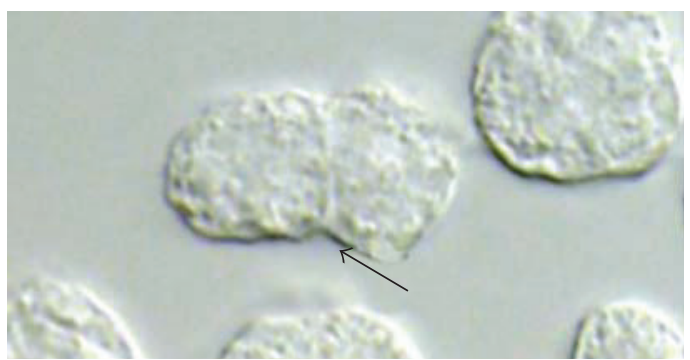

(b)

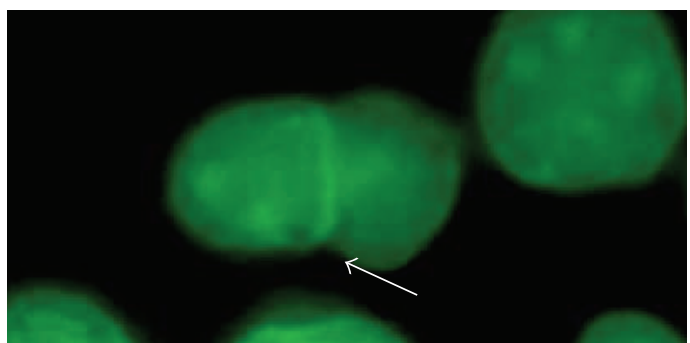

(d)

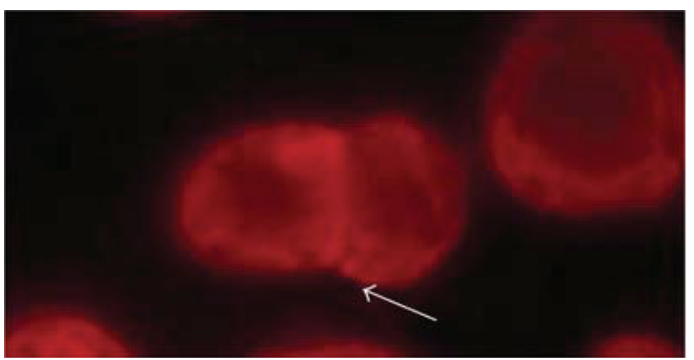

(f)

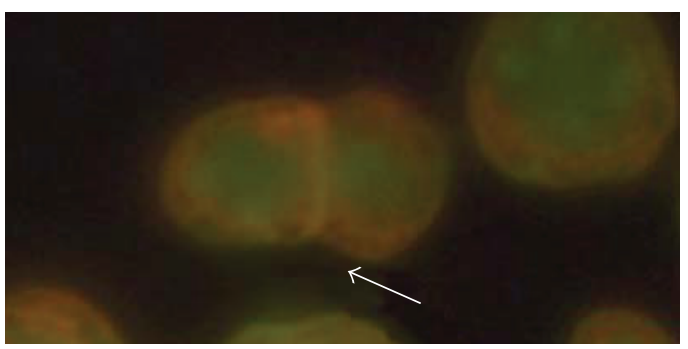

(h)

FIGURe 4: Immunocytochemical detection of the PKC-mediated ZYG1 phosphorylation. Starved GFPCONT and GFP/ZYG1 ${ }^{\mathrm{OE}}$ cells were developed for $2 \mathrm{~h}$, fixed with methanol, and stained by the Phospho-(Ser) PKC Substrate antibody. This was followed by the rhodamineconjugated anti-rabbit secondary antibody to detect the proteins phosphorylated by cPKC, as described in Section 2. Photographs were taken under DIC (a and b) and fluorescence microscope (GFP, (c) and (d); Rhodamine, (e) and (f); GFP and Rhodamine merged, (g) and (h)). Photographs represent the same fields of GFPCONT cells (a, c, e, g) and of GFP/ZYG1 ${ }^{\text {OE }}$ cells (b, d, f, h). GFP protein in GFPCONT cells and GFP/ZYG1 fusion protein in GFP/ZYG1 ${ }^{\mathrm{OE}}$ cells are shown as the green color of GFP (c and d). In GFP/ZYG1 ${ }^{\mathrm{OE}}$ cells, GFP/ZYG1 fusion protein is localized at the region of cell-cell contacts (d; arrow). On the other hand, the localization of GFP protein at the region of cell-cell contacts is not observed in GFPCONT cells (c; arrow). This indicates that its localization is due to the presence of ZYG1, but not to GFP itself. The protein phosphorylated by PKC is shown as the red color of Rhodamine in both cells ((e) and (f)). The protein phosphorylated by PKC is also localized at the region of cell-cell contacts in GFP/ZYG1 ${ }^{\mathrm{OE}}$ cells (f; arrow). This localization shown by Rhodamine is not observed in GFPCONT cells (e; arrow). Since the merged color of GFP and Rhodamine shows yellow in GFP/ZYG1 ${ }^{\mathrm{OE}}$ cells (h; arrow), it is evident that ZYG1 protein is phosphorylated by cPKC at the regions of cell-cell contacts. Bar: $25 \mu \mathrm{m}$. 


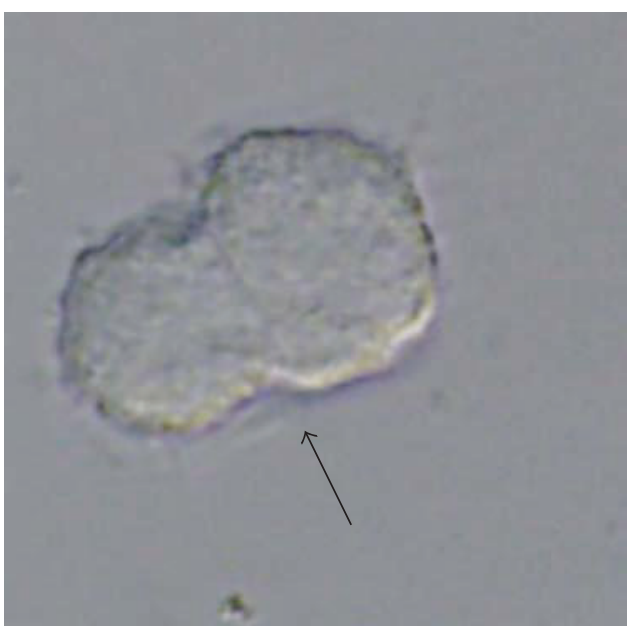

(a)

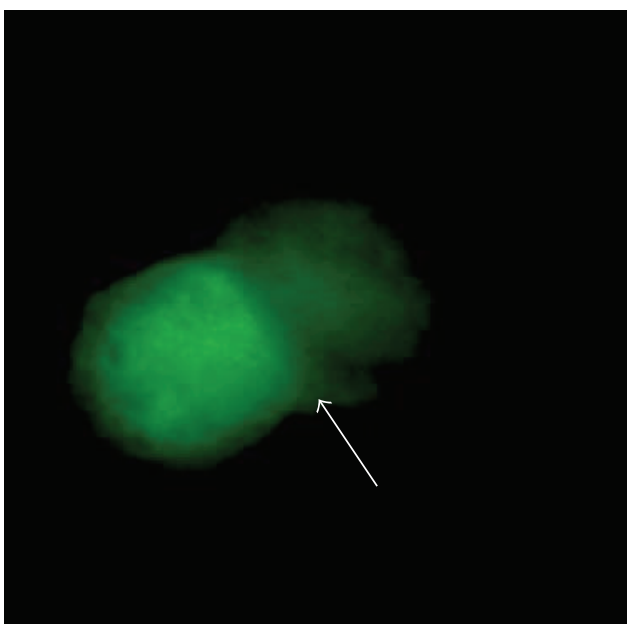

(c)

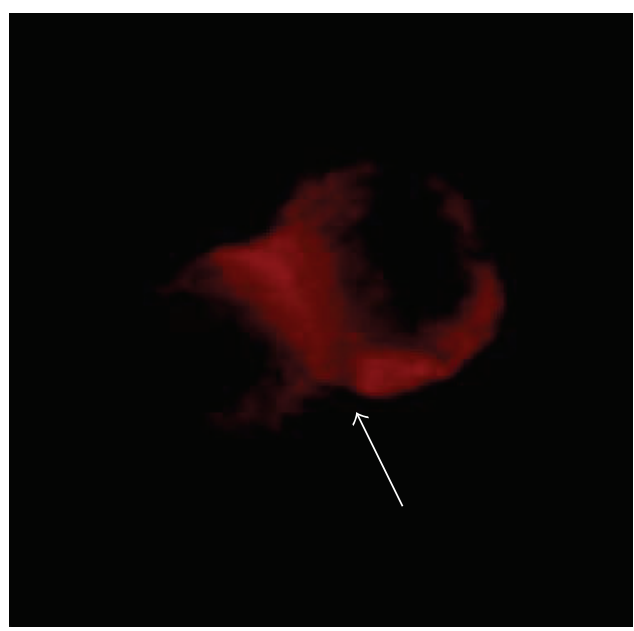

(b)

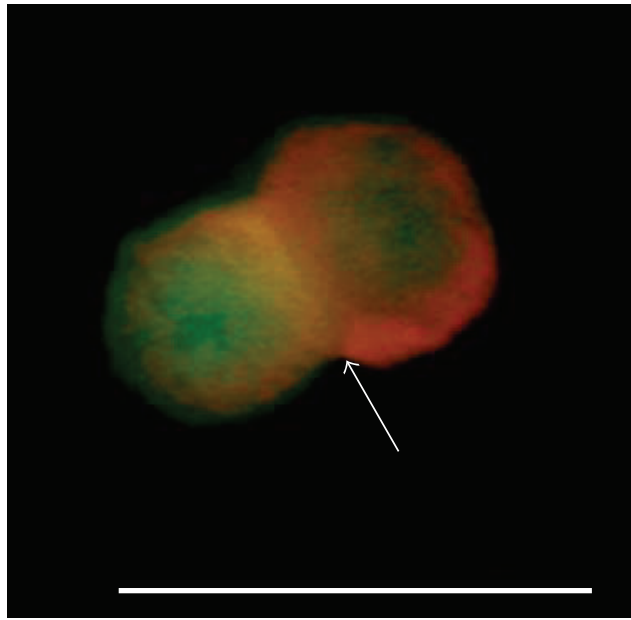

(d)

FIGURE 5: The phosphorylation of GFP/ZYG1 fusion protein by cPKC occurs at the region of cell fusion. Starved GFP/ZYG1 ${ }^{\mathrm{OE}}$ cells were developed for $2 \mathrm{~h}$ in the presence of TPA $(5 \mathrm{nM})$. The sample of GFP/ZYG1 ${ }^{\mathrm{OE}}$ cells for the immunocytochemical detection was prepared as described in Figure 4. The same fields are shown as images of DIC (a), Rhodamine (b), GFP (c), and GFP and Rhodamine merged (d). Since it is evident by the DIC image that there is no boundary between the two cells (a; black arrow), cell fusion is occurring between two cells. Since the merged image shows yellow color (d; a white arrow), it is evident that GFP/ZYG1 fusion protein and proteins phosphorylated by cPKC are colocalized particularly at the region where cell fusion occurred. Bar: $25 \mu \mathrm{m}$.

with those incubated without TPA, thus suggesting that cell fusion in GFP/ZYG1 ${ }^{\mathrm{OE}}$ cells might be accelerated by TPA. Since there is no boundary between the two cells in GFP/ $\mathrm{ZYG1}{ }^{\mathrm{OE}}$ cells incubated with TPA (Figure 5(a); black arrow), it is quite likely that cell fusion actually occurs between them. GFP/ZYG1 fusion protein was co-localized with the proteins phosphorylated by $\mathrm{cPKC}$ at the region of cell fusion, because the image exhibited yellow color around the region of cell fusion occurred (Figure 5; arrows). These results suggest that ZYG1 is phosphorylated by PKC at the region of cell-cell contacts and cell fusion.

Interestingly, the region where cell-cell contacts and cell fusion occurred was found to be composed of a cluster of small vesicles (Figure 2).

3.3. Enforced Expression of ZYG1 Protein in Mouse Myoblasts Induces Their Fusion. $\mathrm{Ca}^{2+}$ and $\mathrm{PKC}$ are known to be involved in myoblast fusion during myogenesis [15-17] and in zygotic cell fusion of Dictyostelium cells [6-9]. Therefore, it is possible that there may be a common signal transduction pathway for cell fusion in both of the cell lines. To know if ZYG1 is able to induce myoblasts, a ha/zygl fusion gene was transfected into $\mathrm{C} 2 \mathrm{C} 12$ cells (myoblasts). In spite of many trials, however, ZYG1 protein was never expressed in $\mathrm{C} 2 \mathrm{C} 12$ cells. For the purpose of ZYG1 expression in mammalian cells, a humanized version ( $m z y g 1$ ) of the $z y g 1$ gene was synthesized in which each amino acid codon was replaced by that most commonly found in mammalian cells (DNA 2.0 Inc.). When a ha/mzyg1 fusion gene (ha/mzygl) was transfected into C2C12 cells, the expression of HA/ZYG1 fusion protein was revealed by the anti-HA antibody (mouse) and then the FITC-conjugated secondary anti-mouse antibody. As a control, C2C12 cells transfected with a vector containing only a ha gene were prepared. At $24 \mathrm{~h}$ of incubation in 


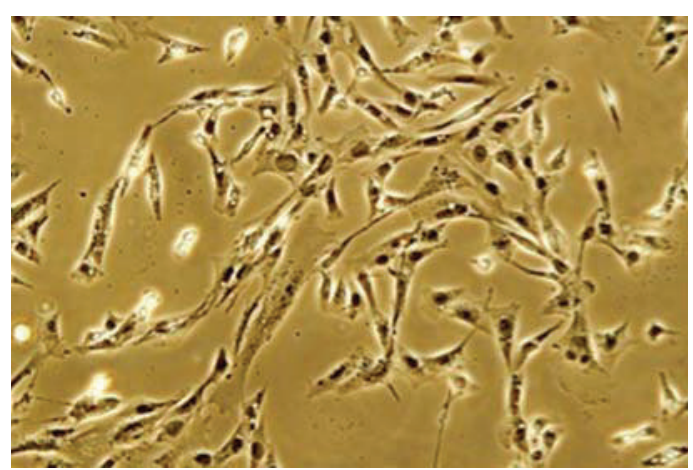

(a)

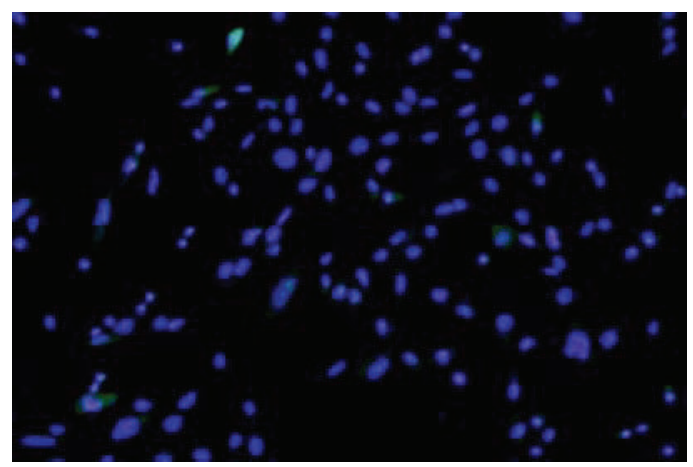

(c)

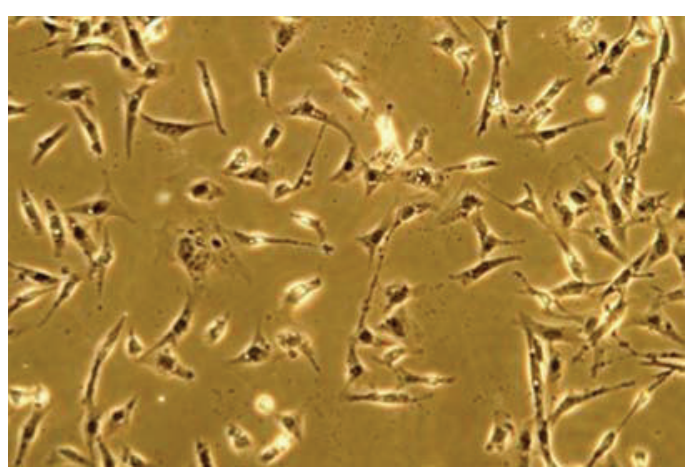

(b)

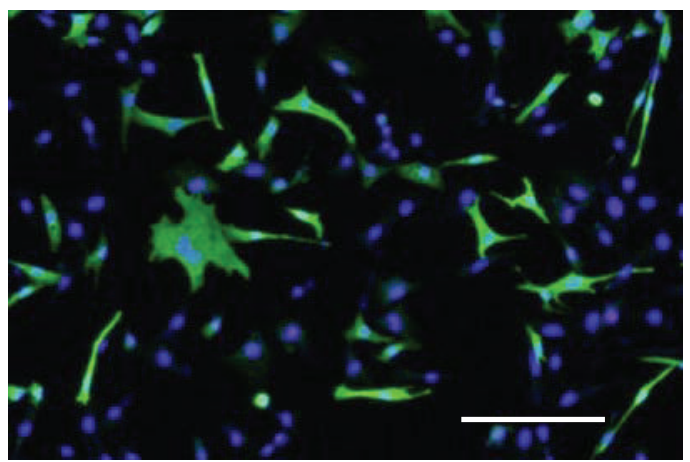

(d)

FIgure 6: Behavior of $\mathrm{C} 2 \mathrm{C} 12$ cells (myoblasts) transfected with the ha/mzygl fusion gene. C2C12 cells were transfected with the ha gene (control; a, c) or ha/mzyg1 fusion gene (HA/ZYG1; b, d), fixed with 4\% paraformaldehyde and stained by antibodies and DAPI according to the methods described in Section 2. Phase-contrast micrographs on the upper sides represent the same field as the merged images of FITC and DAPI on the lower sides ((a) and (c), (b) and (d)). C2C12 cells expressing the HA/ZYG1 fusion protein stained with the anti-HA antibody and then FITC-conjugated anti-mouse secondary antibody are detected as the green-colored cells under a fluorescence microscope though a considerable number of cells are intermingled as untransfected ones in the population (d). Nuclei stained with DAPI are shown as purple color by UV-excitation ( $c$ and d). The transfection rate with the ha/mzygl gene was $36.8 \pm 8 \%$. The expression of HA protein in control cells was scarcely detected (c). Bar: $100 \mu \mathrm{m}$.

DMEM containing 10\% FBS after transfection, cells were fixed with $4 \%$ paraformaldehyde, followed by immunostaining. As a result, cells expressing HA/ZYG1 fusion protein (HA/ZYG1) were recognized because of their green color of fluorescence (Figure 6(d)). The transfection rate was $36 \pm 8 \%$. The expression of HA protein in control cells was scarcely detected though the HA gene was present in the vector used for transfection (Figure 6(c)).

Some HA/ZYG1 cells showed a typical spindle shape as a sign of myoblast fusion (Figure S3(A) see in supplementary material available online at doi:10.1155/2012/657423) though a large number of cells exhibited fibroblast-like morphology. The spindle-shaped cells showed a characteristic alignment that was the parallel apposition of the long axes of myoblasts forming end-to-end alignment as a sign of acquisition of fusion competence (Figure S3(B) see in supplementary material available online at doi:10.1155/2012/657423) [18]. In addition, HA/ZYG1 cells formed giant multinucleate cells frequently (Figure 7) and exhibited fibroblast-like morphology. As binucleate cells were frequently observed to have larger sizes of cells and nuclei (Figure 7(a)), it is quite different from the cells at the mitosis (Figure 44 see in supplementary material available online at doi:10.1155/2012/657423).
The highly elongated cells known as a sign of typical myoblast fusion, in which nuclei were arranged in a single file, were not observed. In addition, nuclei tended to fuse and form a large size of a fused nucleus or nuclei (Figure $7(\mathrm{~d})$ ) though this event was never observed in the normal process of myoblast fusion.

Since the characteristics described above were also observed in control cells, the numbers of cells having multinuclei were counted and statistically analyzed using a pIRES2-AcGFP vector, which contains the $g f p$ gene and expresses constitutively GFP protein independently from the gene inserted. The expression of GFP was weak, but significantly higher compared to GFP-uninfected cells (Figure S5 see in supplementary material available online at doi:10.1155/2012/657423). By transfection with the pIRES2AcGFP vector or pIRES2-AcGFP vector containing an mzyg 1 gene, almost all of the cells expressed GFP or GFP and ZYG1 protein, respectively (Figure S6 see in supplementary material available online at doi:10.1155/2012/657423). Thus, the rates of cell fusion, which were designated as fusion indexes, were found to be significantly higher in cells transfected with the vector containing an mzygl gene than the control cells (Figure 8). The difference of fusion index between GFP cells 


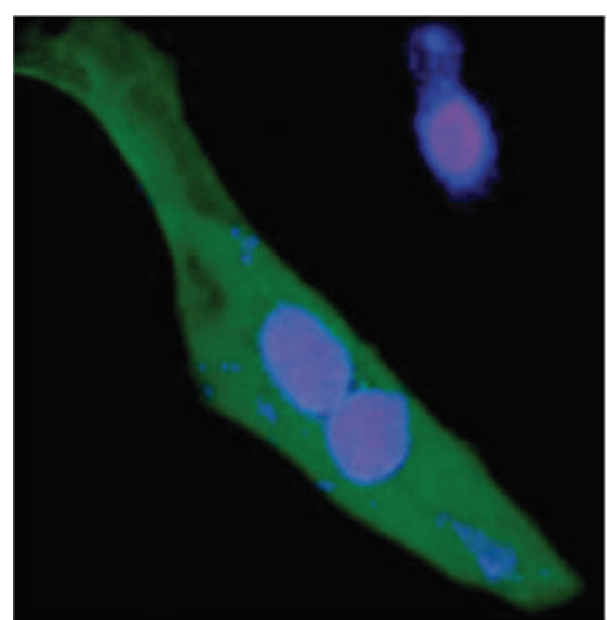

(a)

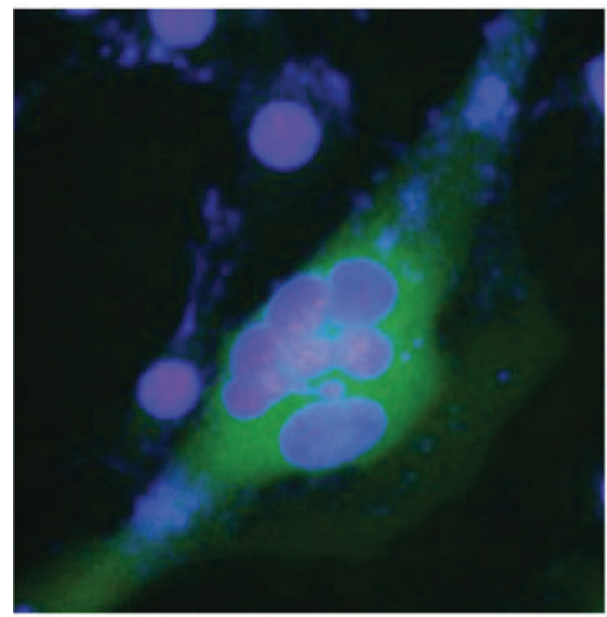

(c)

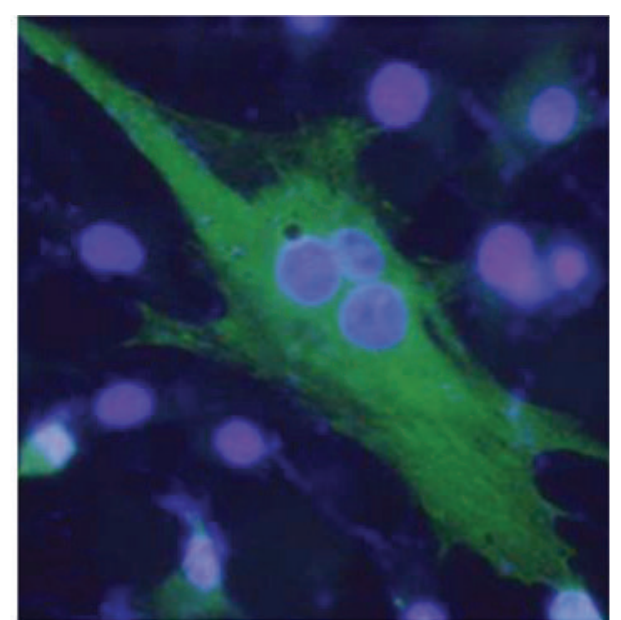

(b)

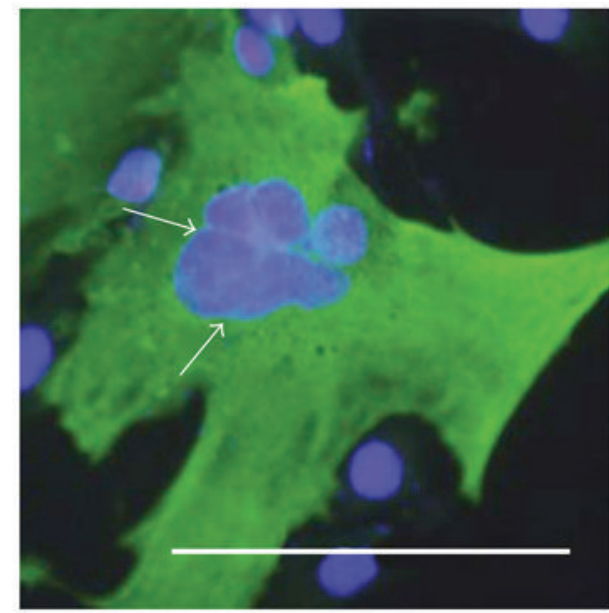

(d)

FIGURE 7: Formation of multinucleate cells in $\mathrm{C} 2 \mathrm{C} 12$ cells transfected with the ha/mzyg1 fusion gene (HA/ZYG1). C2C12 cells were transfected with the ha/mzygl fusion gene, fixed with $4 \%$ paraformaldehyde, and stained by antibodies and DAPI according to the methods described in Section 2. The FITC images merged with DAPI images of large-sized HA/ZYG1 cells containing 2 nuclei (a), 3 nuclei (b), and 7 nuclei (c) are shown. Considering some gulfs observed in a nucleus, it is evident that a large nucleus is formed by nuclear fusion (d; arrows). Bar: $100 \mu \mathrm{m}$.

and GFP and ZYG1 cells was statistically significant $(P<$ 0.002 ), indicating that the myoblast fusion is markedly enhanced by the mzyg1 gene. These results indicate that ZYG1 is able to cause cell fusion in myoblasts.

\section{Discussion}

Previous studies have suggested that the signal transduction pathway via $\mathrm{Ca}^{2+}$ and PKC may participate in sexual fusion (zygote formation) of Dictyostelium cells [10, 12]. Since ZYG1 protein has several deduced sites phosphorylated by PKC, ZYG1 protein was expected to be a likely substrate of PKC. Provided that ZYG1 is phosphorylated by PKC prior to cell fusion, ZYG1 protein will be translocated to the cell membrane where cell fusion occurs.

As presented in this study, the ZYG1 protein was found to actually translocate to the cell cortex including the cell membrane, where cell-cell contacts and subsequent cell fusion occur. Importantly, ZYG1 localizes at the periphery of vesicles including phagocytic cups. Since cell-cell contacts are often observed between phagocytic cups of two facing cells, it is likely that cell fusion may occur through the fusion of those phagocytic cups. The phosphorylation by cPKC of ZYG1 at the regions of cell-cell contacts and cell fusion was verified by Western blot analysis and immunocytochemical study. PKC is a multigene family of serine/threonine (ser/thr) kinases that play critical roles in many signal transduction pathways $[26,27]$. This kinase family is composed of at least 11 different isozymes classified into the following 3 groups: (1) cPKC (conventional) $\alpha, \beta$, and $\gamma$ which require $\mathrm{Ca}^{2+}$ and DAG (diacylglycerol) for maximal activity [28]; (2) nPKC (novel) $\delta, \varepsilon, \eta, \mu$, and $\theta$ isoforms, which are $\mathrm{Ca}^{2+}$ independent but require DAG [29-32]; (3) aPKC (atypical) $\zeta, \lambda$, and $\tau$, which are $\mathrm{Ca}^{2+}$ and DAG insensitive $[33,34]$. Since $\mathrm{Ca}^{2+}$ is required for sexual fusion in Dictyostelium cells [2-4], we used the Phospho-(Ser) PKC Substrate antibody that specifically recognizes cPKC substrates containing phosphoserine. 


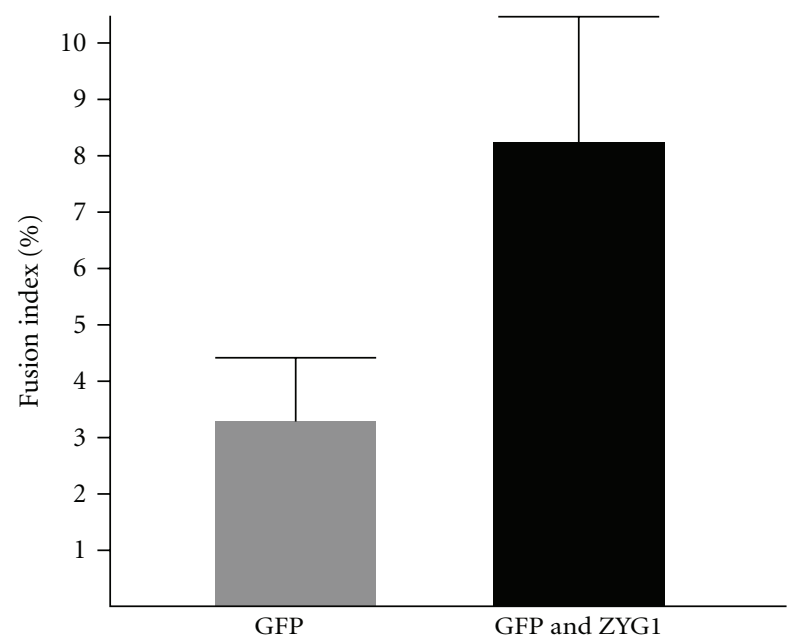

FIGURE 8: Enhanced formation of multinucleate cells by transfecting with the mzygl gene. The percentages of cells containing more than two nuclei are shown as fusion indexes. The pIRES2AcGFP vector or pIRES2-AcGFP vector containing mzyg1 gene was transfected into C2C12 cells as described in Section 2. After 1 day, cells were fixed with $4 \%$ paraformaldehyde and mounted in PBS containing 20\% glycerol and DAPI (final concentration: $2.5 \mu \mathrm{g} / \mathrm{mL}$ ) after three washings with PBS. The numbers of cells and nuclei stained with DAPI were counted. Three samples in two independent experiments were counted (about 500 1,000 cells/sample). The fusion index (ratio of the cell number participated in cell fusion to the total cell number) was calculated by the following formula: Fusion index $(\%)=2 \times$ (The number of cells containing 2 nuclei) + $3 \times$ (The number of cells containing 3 nuclei) $\cdots n \times$ (the number of cells containing $n$ nuclei) $/ 1 \times$ (The number of cells containing 1 nucleus) $+2 \times$ (The number of cells containing 2 nuclei) $+3 \times$ (the number of cells containing 3 nuclei $\cdots n \times$ (The number of cells containing $n$ nuclei) $\times 100$. GFP; $\mathrm{C} 2 \mathrm{C} 12$ cells transfected with the pIRES2-AcGFP vector. GFP and ZYG1; C2C12 cells transfected with the pIRES2-AcGFP vector containing the mzyg1 gene. Bars: standard deviations.

As a result, we found that ZYG1 protein was phosphorylated by cPKC among the PKC family. After homology search, ZYG1 protein has seven sites phosphorylated by cPKC [20]. Among the seven deduced phosphorylation sites, five are serine residues though it is presently unknown if some or all of the serine residues are phosphorylated by cPKC for cell fusion. There are two threonine-phosphorylation sites, but their phosphorylation by cPKC was not detected in our preliminary experiment.

Considering the data presented here, a possible signal transduction pathway involved in sexual cell fusion has been proposed, as follows: (1) cPKC is activated by the increase of intracellular $\mathrm{Ca}^{2+}$. (2) ZYG1 is translocated to the cell membrane. (3) ZYG1 protein is phosphorylated by activated cPKC. (4) The sexual cell fusion is induced by the phosphorylated ZYG1 protein.

Since cPKC is known to be involved in myoblast fusion [15-17], the fusion processes in myoblasts and Dictyostelium cells might share a similar signal transduction pathway. When $\mathrm{C} 2 \mathrm{C} 12$ cells (myoblasts) were transfected with the fusion gene of ha and humanized zygl (ha/mzygl) or
pIRES2-AcGFP vector containing the $m z y g 1$ gene ( $g f p$ and mzyg1), the process of myoblast fusion was found to be accelerated. Since ZYG1 has not a mammalian ortholog, protein(s) other than ZYG1 may be phosphorylated by PKC during myogenesis. However, the result presented here has suggested that ZYG1 is able to take place of the protein phosphorylated by PKC in mammalian cells. Also, the protein phosphorylated by PKC during myoblast fusion may be functionally similar to ZYG1, though the target protein of PKC in myoblasts remains to be identified. The multinucleate cells formed by the transfection with mzyg1, however, exhibited fibroblast-like morphology, while highly elongated cells in which nuclei arrange in a single file as observed in the normal process of myoblast fusion were not formed. The following two explanations for this difference might be possible. During the transfection carried out without FBS for $6 \mathrm{~h}$, myoblasts stop their growth and start differentiation. After a short period of differentation, myoblasts restart growth in the medium containing FBS. As a result, the multinucleate cells formed by cell fusion assume fibroblast-like morphology. Another possibility is that HA/ZYG1 cells might be able to fuse by ZYG1 even under the growth conditions. In all events, it is of importance to note that a novel protein, ZYG1, has an inductive effect on myoblast fusion as well as on sexual fusion of Dictyostelium cells.

\section{Acknowledgments}

The authors are grateful to Professor Michael MacManus (Miyagi University of Education) for his critical reading and insightful comments of the paper. They are also grateful to Dr. Kazumasa Ohashi of Tohoku University for providing them with the vector (pUCD2 SR $\alpha$ ). They also would like to thank Drs. Yutaka Miyazawa and Hideyuki Takahashi of Tohoku University for the use of a confocal microscopy and Mr. Takefumi Yamamoto of Shiga University of Medical Science for his technical assistance in using a confocal microscopy.

\section{References}

[1] M. F. Filosa and R. E. Dengler, "Ultrastructure of macrocyst formation in the cellular slime mold, Dictyostelium mucoroides: extensive phagocytosis of amoebae by a specialized cell," Developmental Biology, vol. 29, no. 1, pp. 1-16, 1972.

[2] A. W. Nickerson and K. B. Raper, "Macrocysts in the life cycle of the Dictyosteliaceae. II. Germination of the macrocyst," The American Journal of Botany, vol. 60, pp. 247-253, 1973.

[3] D. Francis, "Macrocyst genetics in Polysphondylium pallidum, a cellular slime mould," Journal of General Microbiology, vol. 89, no. 2, pp. 310-318, 1975.

[4] M. A. Wallace and K. B. Raper, "Genetic exchanges in the macrocysts of Dictyostelium discoideum," Journal of General Microbiology, vol. 113, no. 2, pp. 327-337, 1979.

[5] A. Amagai, "Induction of zygote formation by ethylene during the sexual development of the cellular slime mold Dictyostelium mucoroides," Differentiation, vol. 41, no. 3, pp. 176-183, 1989.

[6] T. Suzuki, A. Amagai, and Y. Maeda, "Cyclic AMP and $\mathrm{Ca}^{2+}$ as regulators of zygote formation in the cellular slime mold 
Dictyostelium mucoroides," Differentiation, vol. 49, no. 3, pp. 127-132, 1992.

[7] A. H. Chagla, K. E. Lewis, and D. H. O’Day, " $\mathrm{Ca}^{2+}$ and cell fusion during sexual development in liquid cultures of Dictyostelium discoideum," Experimental Cell Research, vol. 126, no. 2, pp. 501-505, 1980.

[8] S. P. Szabo, D. H. O’Day, and A. H. Chagla, "Cell fusion, nuclear fusion, and zygote differentiation during sexual development of Dictyostelium discoideum," Developmental Biology, vol. 90, no. 2, pp. 375-382, 1982.

[9] K. E. Gunther, H. Ramkisson, M. A. Lydan, and D. H. O'Day, "Fertilization in Dictyostelium: pharmacological analyses and the presence of a substrate protein suggest protein kinase $\mathrm{C}$ is essential for gamete fusion," Expermental Cell Research, vol. 220, pp. 325-331, 1995.

[10] A. Amagai, "Ethylene as a potent inducer of sexual development," Development Growth and Differentiation, vol. 53, pp. 617-623, 2011.

[11] S. Kawai, Y. Maeda, and A. Amagai, "Promotion of zygote formation by protein kinase inhibitors during the sexual development of Dictyostelium mucoroides," Development Growth and Differentiation, vol. 35, no. 5, pp. 601-607, 1993.

[12] A. Amagai, "A novel function of ethylene," Gene Regulation and Systems Biology, vol. 3, pp. 21-30, 2009.

[13] M. J. Wakelam, "The fusion of myoblasts," Biochemical Journal, vol. 228, no. 1, pp. 1-12, 1985.

[14] K. M. Jansen and G. K. Pavlath, "Molecular control of mammalian myoblast fusion," Methods in Molecular Biology, vol. 475, pp. 115-133, 2008.

[15] A. Shainberg, G. Yagil, and D. Yaffe, "Control of myogenesis in vitro by $\mathrm{Ca}^{2+}$ concentration in nutritional medium," Experimental Cell Research, vol. 58, no. 1, pp. 163-167, 1969.

[16] B. Paterson and R. C. Strohman, "Myosin synthesis in cultures of differentiating chicken embryo skeletal muscle," Developmental Biology, vol. 29, no. 2, pp. 113-138, 1972.

[17] J. D. David, C. R. Faser, and G. P. Perrot, "Role of protein kinase C in chick embryo skeletal myoblast fusion," Developmental Biology, vol. 139, no. 1, pp. 89-99, 1990.

[18] J. D. David and C. A. Higginbotham, "Fusion of chick embryo skeletal myoblasts: interactions of prostaglandin E1, cAMP, and calcium influx," Developmental Biology, vol. 82, no. 2, pp. 308-316, 1981.

[19] J. D. David, W. M. See, and C. A. Higginbotham, "Fusion of chick embryo skeletal myoblasts: role of calcium influx preceding membrane union," Developmental Biology, vol. 82, no. 2, pp. 297-307, 1981.

[20] A. Amagai, "Involvement of a novel gene, zyg1, in zygote formation of Dictyostelium mucoroides," Journal of Muscle Research and Cell Motility, vol. 23, no. 7-8, pp. 867-874, 2002.

[21] A. Amagai, S. S. Soramoto, S. H. Saito, and Y. Maeda, "Ethylene induces zygote formation through an enhanced expression of zyg1 in Dictyostelium mucoroides," Experimental Cell Research, vol. 313, no. 11, pp. 2493-2503, 2007.

[22] A. Luria, T. Tennenbaum, Y. S. Qing, S. Rubinstein, and H. Breitbart, "Differential localization of conventional protein kinase C isoforms during mouse oocyte development," Biology of Reproduction, vol. 62, no. 6, pp. 1564-1570, 2000.

[23] J. T. Bonner, "Evidence for the formation of cell aggregates by chemotaxis in the development of the slime mold Dictyostelium discoideum," Journal of Experimental Zoology, vol. 106, pp. 1-26, 1947.

[24] N. Yang, O. Higuchi, K. Ohashi et al., "Cofflin phosphorylation by LIM-kinase 1 and its role in Rac-mediated actin reorganization," Nature, vol. 393, no. 6687, pp. 809-812, 1998.
[25] P. K. Howard, K. G. Ahern, and R. A. Firtel, "Establishment of a transient expression system for Dictyostelium discoideum," Nucleic Acids Research, vol. 16, no. 6, pp. 2613-2623, 1988.

[26] Y. Nishizuka, "Intracellular signaling by hydrolysis of phospholipids and activation of protein kinase C," Science, vol. 258, no. 5082, pp. 607-614, 1992.

[27] H. Hug and T. F. Sarre, "Protein kinase C isoenzymes: divergence in signal transduction?” Biochemical Journal, vol. 291, no. 2, pp. 329-343, 1993.

[28] J. L. Knopf, M. Lee, L. A. Kritz, C. R. Loomis, R. M. Hewick, and R. M. Bell, "Cloning and expression of multiple protein kinase C cDNAs," Cell, vol. 46, pp. 491-502, 1986.

[29] F. J. Johannes, J. Prestle, S. Eis, P. Oberhagemann, and K. Pfizenmaier, "PKCu is a novel, atypical member of the protein kinase C family," Journal of Biological Chemistry, vol. 269, no. 8, pp. 6140-6148, 1994.

[30] Y. Ono, T. Fujii, K. Ogita, U. Kikkawa, K. Igarashi, and Y. Nishizuka, "The structure, expression, and properties of additional members of the protein kinase C family," Journal of Biological Chemistry, vol. 263, no. 14, pp. 6927-6932, 1988.

[31] S. I. Osada, K. Mizuno, T. C. Saido et al., "A phorbol ester receptor/protein kinase, $\mathrm{nPKC}$ eta, a new member of the protein kinase $\mathrm{C}$ family predominantly expressed in lung and skin," Journal of Biological Chemistry, vol. 265, no. 36, pp. 22434-22440, 1990.

[32] S. I. Osada, K. Mizuno, T. C. Saido, K. Suzuki, T. Kuroki, and S. Ohno, "A new member of the protein kinase $\mathrm{C}$ family, $\mathrm{nPKC}$ theta, predominantly expressed in skeletal muscle," Molecular and Cellular Biology, vol. 12, no. 9, pp. 3930-3938, 1992.

[33] Y. Ono, T. Fujii, K. Ogita, U. Kikkawa, K. Igarashi, and Y. Nishizuka, "Protein kinase $\mathrm{C} \zeta$ subspecies from rat brain: its structure, expression, and properties," Proceedings of the $\mathrm{Na}$ tional Academy of Sciences of the United States of America, vol. 86, no. 9, pp. 3099-3103, 1989.

[34] L. A. Selbie, C. Schmitz-Peiffer, Y. Sheng, and T. J. Biden, "Molecular cloning and characterization of PKC2, an atypical isoform of protein kinase $\mathrm{C}$ derived from insulin-secreting cells," Journal of Biological Chemistry, vol. 268, no. 32, pp. 24296-24302, 1993. 

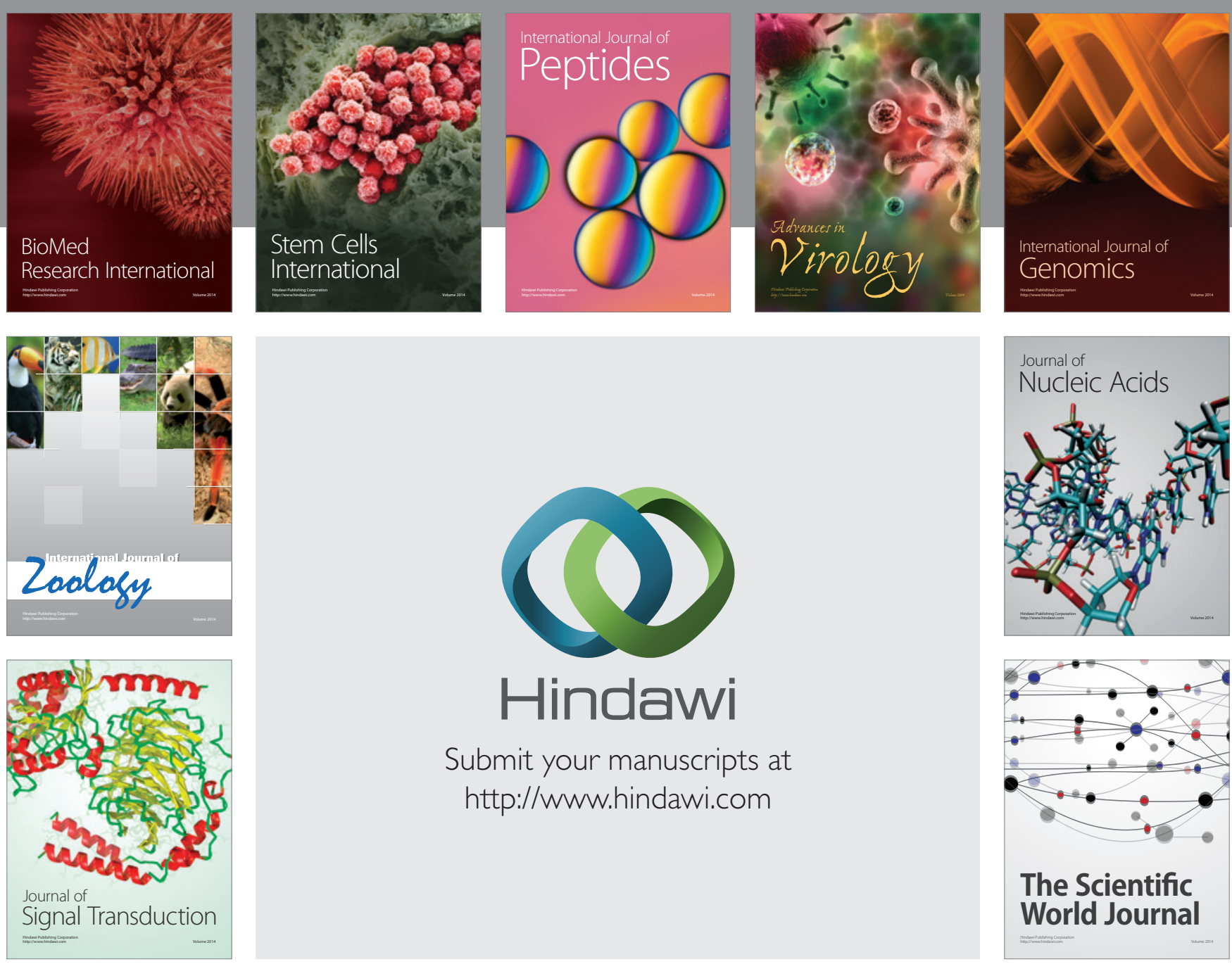

Submit your manuscripts at

http://www.hindawi.com
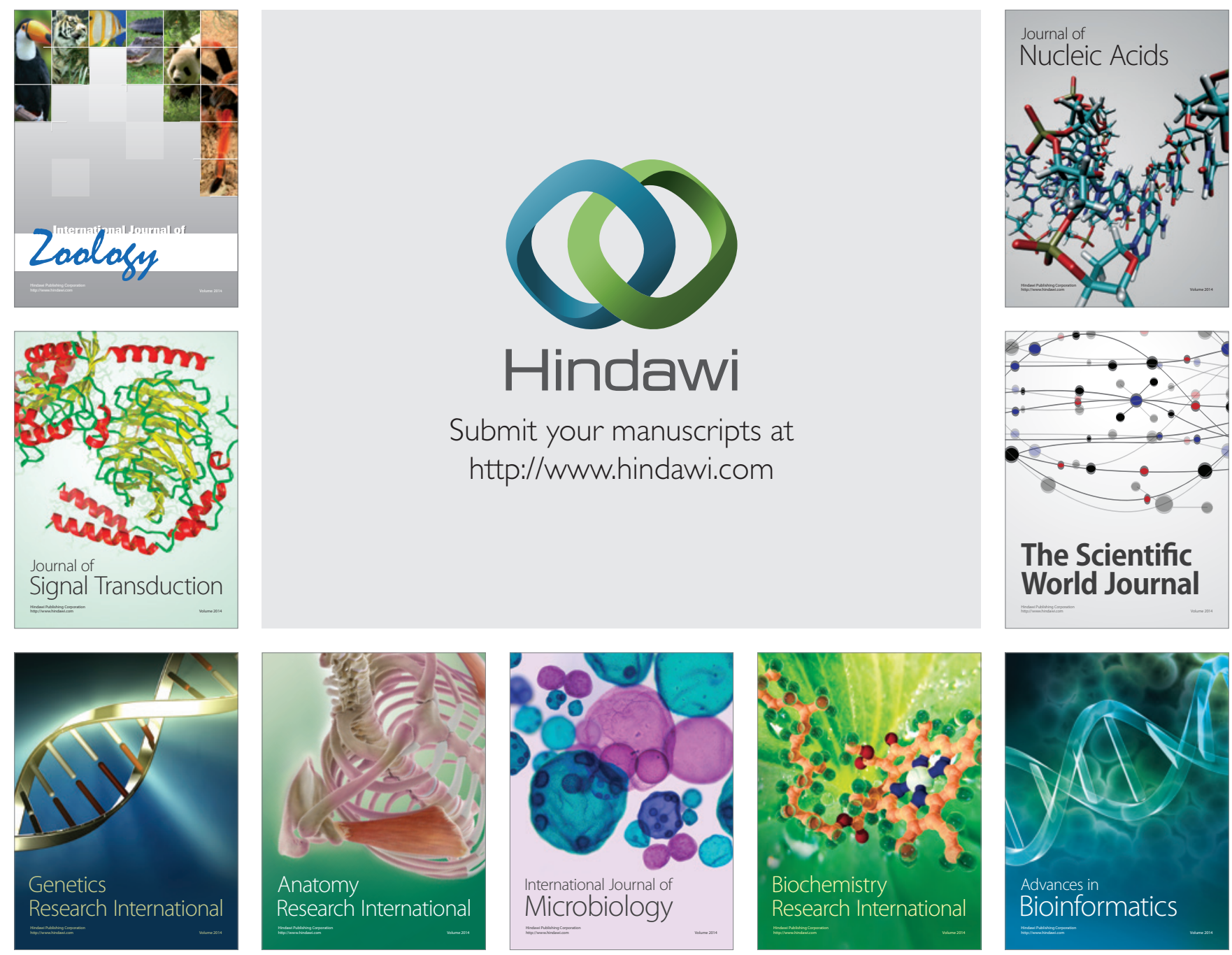

The Scientific World Journal
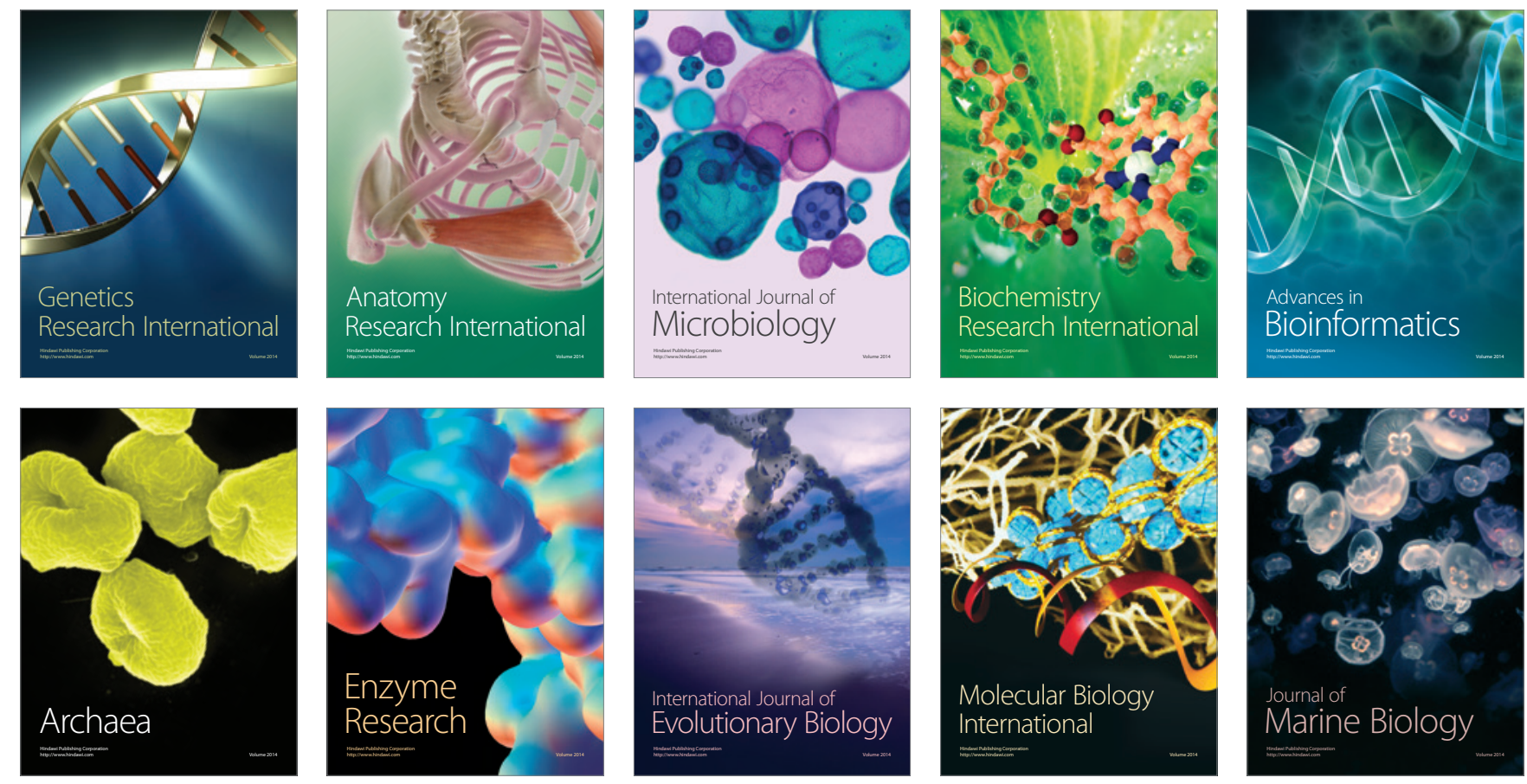